Journal of

CONTACT LENS

RESEARCH \& SCIENCE-

Original Article

\title{
CONJUNCTIVAL INLAPSE: NASAL AND TEMPORAL CONJUCTIVAL SHAPE VARIATIONS ASSOCIATED WITH SCLERAL LENS WEAR
}

\section{Conjunctival Inlapse}

By Claudine Courey, OD, MSc, FAAO, ${ }^{1}$ Gabriella Courey, ${ }^{2}$ and Langis Michaud, OD, MSc, FAAO (Dipl), FSLS, FBCLA, FEAOO 3

${ }^{1}$ Clinical Instructor, Université de Montréal

${ }^{2}$ Undergraduate optometry student, Université de Montréal

${ }^{3}$ Professor, Université de Montréal

Corresponding Author: langis.michaud@umontreal.ca

Submitted: February 12, 2018. Accepted: May 10, 2018. Published: May 18, 2018.

\section{ABSTRACT}

\section{Purpose}

This article aims to report a new clinical finding associated with the wear of scleral lenses.

\section{Methods}

Non-contact lens wearer subjects were recruited and fitted with large diameter $(18 \mathrm{~mm})$ scleral lenses. Lenses were randomly filled with non-preserved saline or non-preserved carboxymethylcellulose-based artificial tears (Refresh Celluvisc, Allergan, Ca). The sinking of the lens on the nasal and temporal sclera was as-sessed periodically during a total of $6 \mathrm{~h} 00$ of wear, with the use of anterior segment coherence tomography (OCT- Optovue, Clarion Technologies, Texas). Images were taken every 30 minutes for the first $2 \mathrm{~h} 00$, then at $4 \mathrm{~h} 00$ and $6 \mathrm{~h} 00$ post insertion.

\section{Results}

The nasal side sinks significantly more than the temporal side by $23.0 \pm 7.3 \mu \mathrm{m}(\mathrm{F}[1,12]=10.043 ; \mathrm{p}=0.008$; $95 \% \mathrm{CI}:[7.2,38.9])$. This difference is significant with time $(\mathrm{F}=8.757 ; \mathrm{p}<0.001)$ and there is a side effect $(\mathrm{F}=10.043 ; \mathrm{p}=0.008)$. The type of solution does not influence the lens behaviour $(\mathrm{F}=0.250 ; \mathrm{p}=0.626)$. A new clinical finding was revealed during scan analysis. Conjunctival tissue displacement was seen, under the reverse curve of the scleral lens, shortly after insertion. This conjunctival "inlapse" (CI) was sustained over all the wearing hours. On the nasal quadrant, CI was reduced in height and present in only 8/15 subjects while, in the temporal quadrant, $100 \%$ of subjects showed an average $\mathrm{CI}$ of $38.39 \pm 10.43 \mu \mathrm{m}(\mathrm{t}[84]=3.68$; $\mathrm{p}=0.0072 ; 95 \% \mathrm{CI}[17.64,59.13]) 30$ minutes post insertion followed by a non-significant decrease of 1.97 $\pm 10.34 \mu \mathrm{m}(\mathrm{t}[84]=0.19 ; \mathrm{p}=1.00 ; 95 \% \mathrm{CI}[-22.52,18.58])$ between 30 minutes and 6 hours of wear. 


\section{Conclusion}

Nasal sinking is more pronounced as compared with temporal lens sinking. This may explain the occurrence of a new clinical phenomenon identified to happen shortly after lens insertion, under the reverse curve of a scleral lens. In fact, CI happens mostly on the temporal quadrant, where more space is available for the conjunctival tissue to move. This finding suggests that conjunctival tissue reacts to scleral lens wear, not only in the inferior quadrant, where conjunctival prolapse is known to occur, but in every other one as well.

Modern-day scleral contact lenses (SCL) are widely used to treat ocular surface disease, ${ }^{1}$ to optically correct corneal irregularities and opacities, and to a lesser extent, to correct high refractive error, astigmatism ${ }^{2}$ and presbyopia on normal corneas. ${ }^{3}$ Despite this increased popularity over the last years, the fitting of SCL may remain a challenge because of the complex relationship between the lens design and the ocular surface.

In fact, it is known that the conjunctiva is a highly non-rotational and asymmetrical surface. ${ }^{4}$ There is a high inter-individual variability; some conjunctiva are almost spherical, a few are symmetrically toric, while the most common profile is characterized by irregularly spaced elevations and depressions. ${ }^{5}$ Larger SCL, namely $18 \mathrm{~mm}$ and over, present more than a $6 \mathrm{~mm}$ bearing on the conjunctiva on the average subject, ${ }^{6}$ which represents a challenge to achieve an optimal lens-to-conjunctiva relationship. To be well fitted, the lens' peripheral curves should align with the conjunctiva in every quadrant. This is where it becomes difficult to fit larger scleral lenses without designing custom toric peripheries. ${ }^{7}$

Despite optimal fitting, SCL worn for a short period results in significant tissue compression of the conjunctival and episcleral layers, which remains not recovered $3 \mathrm{~h} 00$ post-wear, provided that diurnal variation of the tissue was taken in account. ${ }^{8}$ In 2017 , a study was conducted to determine the mean settling rate of a large $\mathrm{SCL}^{9}$ and the behaviour of the lens's nasal and temporal sinking rates were evaluated.

This article aims to present these results, highlighting the fact that a new clinical finding arose from this data analysis, which sheds light on the behaviour of the conjunctiva over the course of the entire day while wearing a scleral lens.

\section{MATERIALS AND METHODS}

Material and methods for the study were described in details elsewhere. ${ }^{9}$ This prospective study was approved by the University of Montreal review board and ethics committee in Health Sciences and adhered to the tenants of the Declaration of Helsinki. It was conducted at the Clinique Universitaire de la Vision, University of Montreal by the main author. All participants were explained the goal, purpose, potential risks, and benefits and provided informed consent.

To summarize, 15 subjects were recruited and assigned to wear $18 \mathrm{~mm}$ SCL (MSD, Laboratoires Blanchard, Sherbrooke, Quebec), randomly fitted with various filling solutions (gel and saline). Conjunctiva meridional sagittal height was evaluated with the use of a profilometer (Eaglet Eye, The Netherlands). Data on lens sinking was collected at baseline, every 30 minutes for the first $2 \mathrm{~h} 00$ of wear and every $2 \mathrm{~h} 00$ until the last visit (6h post insertion). OCT images (Optovue, Clarion technology, Texas, USA) were recorded showing the lens sinking on the conjunctiva, in the nasal and the temporal quadrants. For this purpose, the subject was asked to look at a target (light) at a specific angle (30 deg). Image uptake and analysis were performed by the same examiner.

\section{STATISTICAL ANALYSIS}

The effect of time post insertion on conjunctival variations was done using an analysis of variance for repeated measures with two repeated factors; time in minutes $(0,30,60,90,120,240,360)$ and treatment (saline and gel). In case of significant time effect, a post-hoc analysis using Tukey-Kramer contrast was done.

To study the effect of the side of the lens with respect to conjunctival variations, an ANOVA for repeated

J Cont Lens Res Sci Vol 2(1):e38-e48; May 18, 2018.

This article is distributed under the terms of the Creative Commons Attribution-Non Commercial 4.0 International License. 
measures with three factors (time and treatment, as well as the factor of side [nasal and temporal]), was conducted.

\section{RESULTS}

The complete set of results for lens sinking is presented in Table 1 and some were already reported. ${ }^{9}$ However, it is important to keep this data in mind to understand the other elements presented here. It is as important to remember that there is huge variability among patients due to the different characteristics of the conjunctival and scleral tissue.

\section{Conjunctival Profile}

Sagittal height of the nasal conjunctiva was, in average, $3118.0 \pm 90.8 \mathrm{um}$, compared to the temporal sagittal height measured at $3338 \pm 97.6 \mathrm{um}$, both evaluated at $14 \mathrm{~mm}$ of chord. This difference of 210 um is found significant $(\mathrm{p}=0.003)$.

\section{Average Nasal Sink}

Lenses fitted with gel solution showed a conjunctival compression of $85.6 \pm 48.8$ um at baseline, evolving to $129.1 \pm 15.8$ um after 6 h00 of wear. Similar findings are found if lenses are filled in with saline, showing $89.0 \pm 40.9$ um at baseline, and ending at $127.7 \pm 33.6$ um at the end of the study. As it appears, the effect of the factor of time is considered significant $(\mathrm{F}=7.04$ $\mathrm{p}<0.001)$, but the solution does not influence the sinking rate $(\mathrm{F}=0.01 ; \mathrm{p}=0.9355)$. Results are presented in Figure 1 Consequently, the interaction between time and treatment is non significant $(\mathrm{F}=0.84 ; \mathrm{p}=0.5421)$. This means that scleral lens increases its sinking in the conjunctiva with time, independently of the solution used to fill in the bowl. As it is displayed in Figure 1 , most of the movement occurs during the first 30 minutes of wear, followed by a small increase over time. More precisely, the effect of time post insertion proved to be statistically significant showing a mean nasal sink variation of $41.4 \pm 7.0 \mu \mathrm{m}(\mathrm{t}[84]=5.91$; $\mathrm{p}<0.0001 ; 95 \% \mathrm{CI}[27.5,55.4])$ after 6 hours of wear. A significant decrease of $28.8 \pm 7.0 \mu \mathrm{m}(\mathrm{t}[84]=4.11$; $\mathrm{p}=0.0017 ; 95 \% \mathrm{CI}[14.9,42.8])$ was noted 30 minutes post insertion, followed by a non- significant decrease of $12.6 \pm 7.0 \mu \mathrm{m}(\mathrm{t}[84]=1.81 ; \mathrm{p}=0.5482 ; 95 \% \mathrm{CI}[-1.3$, 26.41]) between 30 minutes and 6 hours of wear.

\section{Average Temporal Sink}

Lenses fitted with gel solution showed a lower conjunctival compression, compared to nasal, of $71.6 \pm 37.2$ um at baseline, evolving to $93.7 \pm 23.1$ um after $6 \mathrm{~h} 00$ of wear. Similar variations are found if lenses are filled in with saline, evolving from

FIG. 1 Nasal sink for gel solution and saline solution.

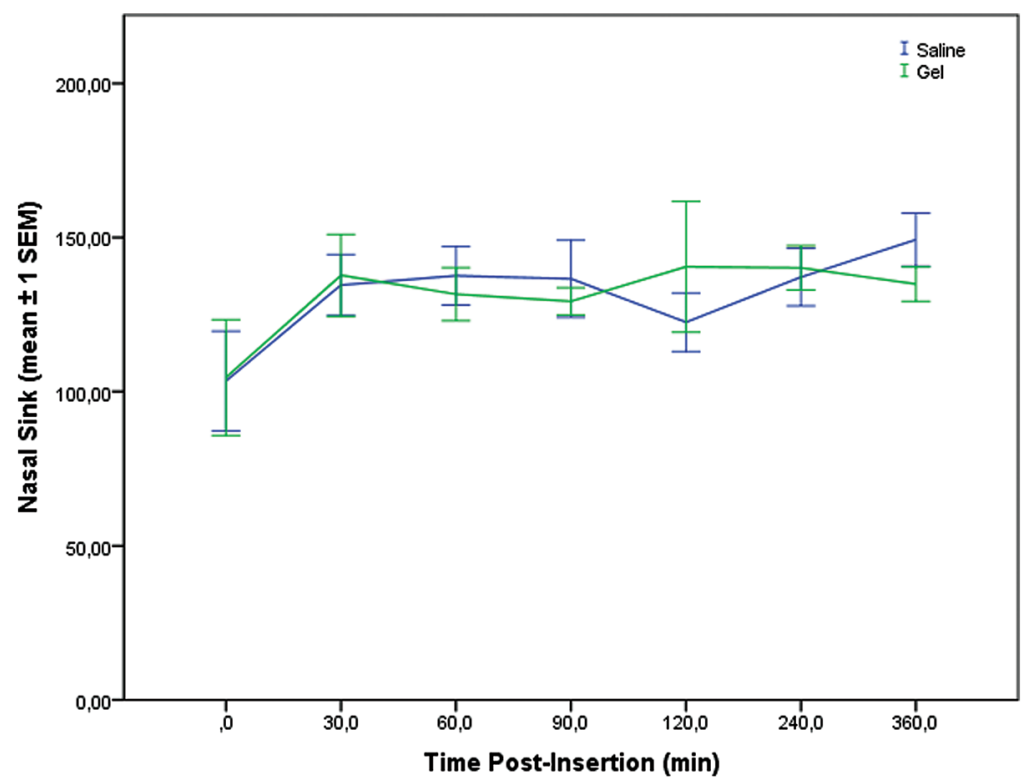

J Cont Lens Res Sci Vol 2(1):e38-e48; May 18, 2018.

This article is distributed under the terms of the Creative Commons Attribution-Non Commercial 4.0 International License. 


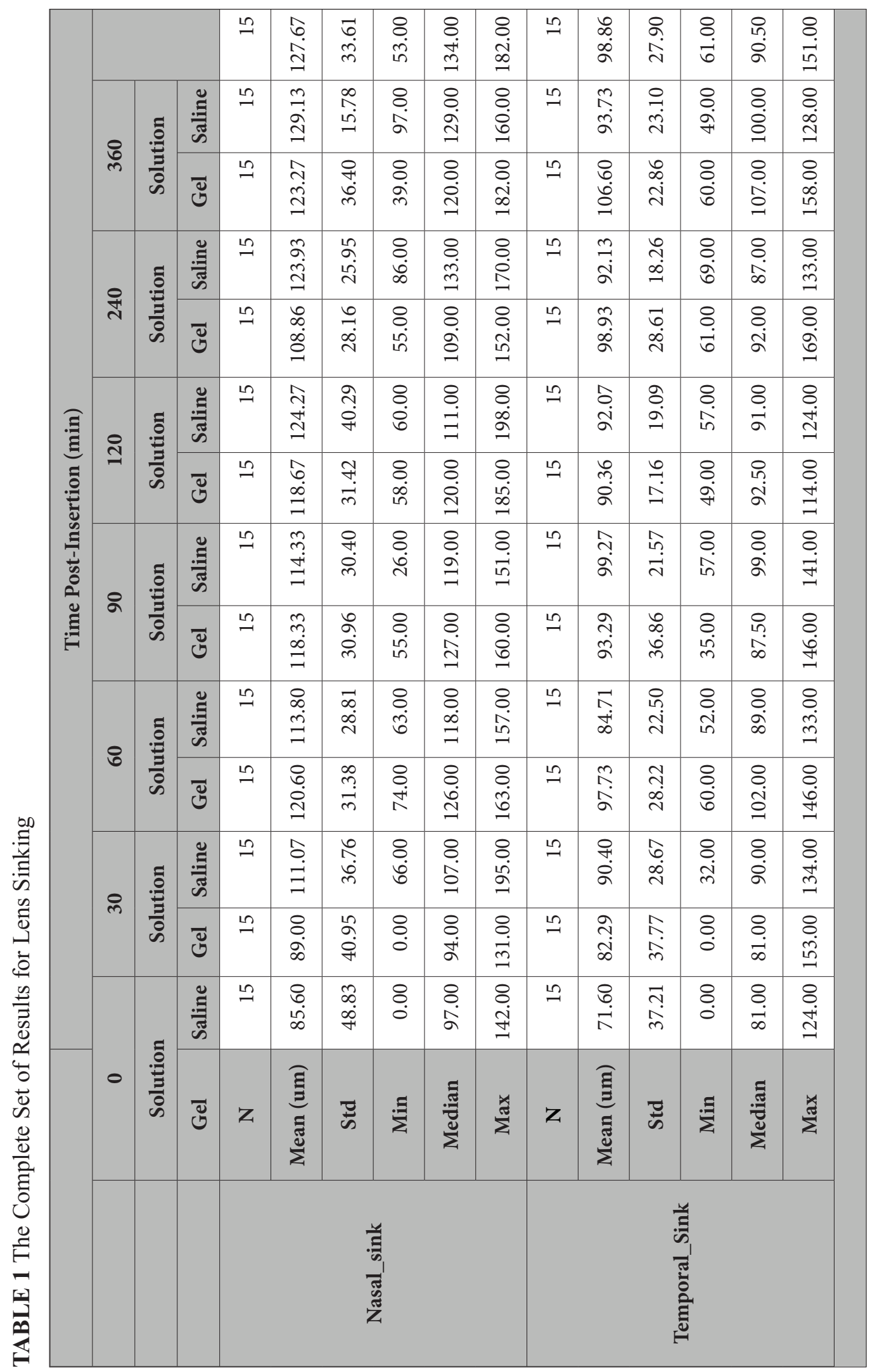

J Cont Lens Res Sci Vol 2(1):e38-e48; May 18, 2018.

This article is distributed under the terms of the Creative Commons Attribution-Non Commercial 4.0 International License. 
$82.3 \pm 37.8 \mathrm{um}$ at baseline to $98.9 \pm 27.9 \mathrm{um}$ at the end of the study. The same statistical differences are found compared to the nasal quadrant: there was an effect of the factor of time $(F=3.53 ; p=0.0037)$ but not based on the type of solution used (saline vs. gel, $\mathrm{F}=1.34 ; \mathrm{p}=0.2662$ ). Consequently, the interaction between time and treatment was not significant $(\mathrm{F}=1.01 ; \mathrm{p}=0.4220)$. The increased sinking of the lens proved to be statistically significant after 6 hours of wear $(\mathrm{t}[83]=3.54 ; \mathrm{p}=0.0114 ; 95 \% \mathrm{CI}[8.9,31.8])$. A significant decrease of $17.3 \pm 5.71 \mu \mathrm{m}(\mathrm{t}[83]=3.03$; $\mathrm{p}=0.0491 ; 95 \% \mathrm{CI}[5.9,28.7])$ was noted 30 minutes post insertion followed by a non-significant decrease of $3.1 \pm 5.7 \mu \mathrm{m}(\mathrm{t}[83]=0.054 ; \mathrm{p}=0.9982 ; 95 \% \mathrm{CI}[-8.3,14.4])$ between 30 minutes and 6 hours of wear.

\section{Comparison: Nasal sink versus Temporal Sink}

As previously noted the nasal side sinks significantly more than the temporal side by $23.0 \pm 7.3 \mu \mathrm{m}$ $(F[1,12]=10.043 ; p=0.008 ; 95 \% C I:[7.2,38.9])$. This difference is significant with time $(\mathrm{F}=8.757 ; \mathrm{p}<0.001)$ and there is a side effect $(\mathrm{F}=10.043 ; \mathrm{p}=0.008)$. This is the same finding if we use saline or gel, the type of solution does not influence the lens behaviour $(\mathrm{F}=0.250 ; \mathrm{p}=0.626)$.

\section{A New Clinical Finding}

Upon analysis of temporal and nasal scans (OCTs), a new clinical finding was discovered. In fact, there was a movement of the conjunctival tissue, bulging under the surface of the lens, near the location of the reverse curve. This conjunctival movement was not present at baseline (Figure 3) but noted early after lens insertion and sustained over all the wearing hours (Figure 4). By analogy to the known conjunctival prolapse, already described, ${ }^{10}$ we suggest using the term of conjunctival inlapse (CI) to describe this new phenomenon.

The CI was measured identically for every patient to ensure repeatability. A first line (A) was drawn from the outer edge of the lens all the way to the innermost end of the CI. Following this measurement, a second line (B), now perpendicular to line A, was drawn to connect the apex of the $\mathrm{CI}$ to the line A. The height of the CI was measured by the magnitude of line B, in microns.

CI occurred differently on nasal and temporal quadrants (see Table 2). As for the nasal quadrant, CI was significantly different based on time and the type of solution used. At baseline, $10 \%$ of the subjects fitted with gel in the lens presented CI, reaching a peak

FIG 2 Temporal sink for gel solution and saline solution.

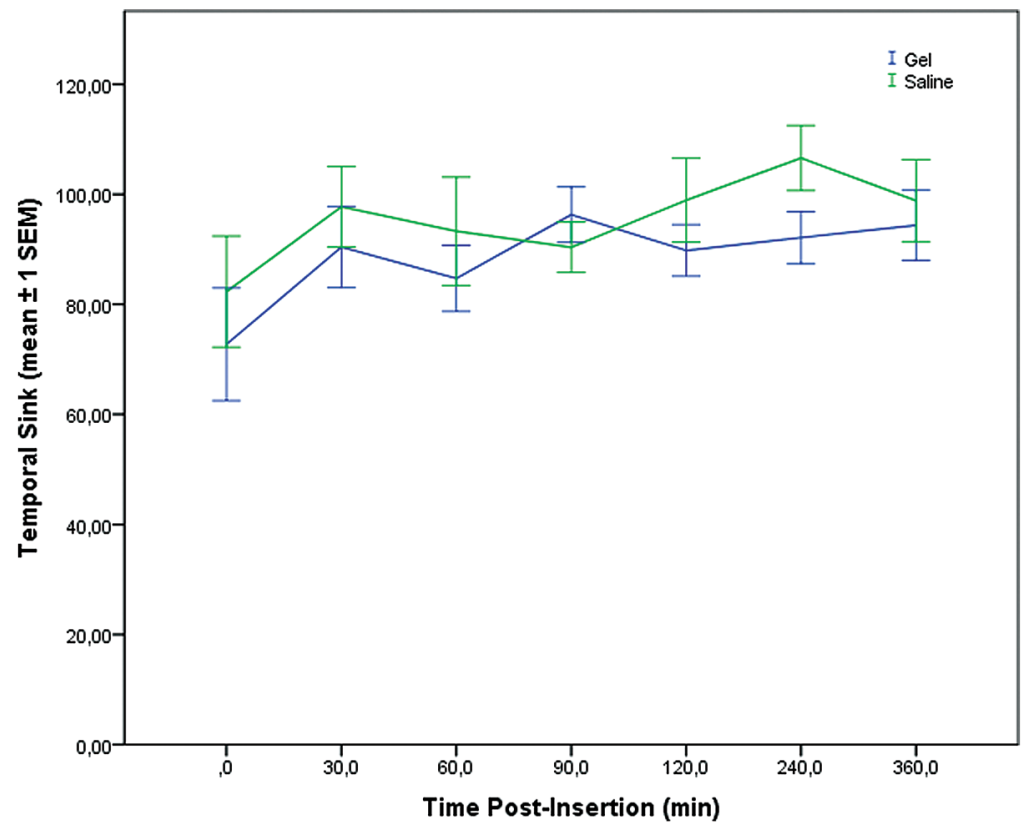

J Cont Lens Res Sci Vol 2(1):e38-e48; May 18, 2018.

This article is distributed under the terms of the Creative Commons Attribution-Non Commercial 4.0 International License. 
FIG. 3 Analysis of temporal and nasal scans showing conjunctival movement not present at baseline. T=0.

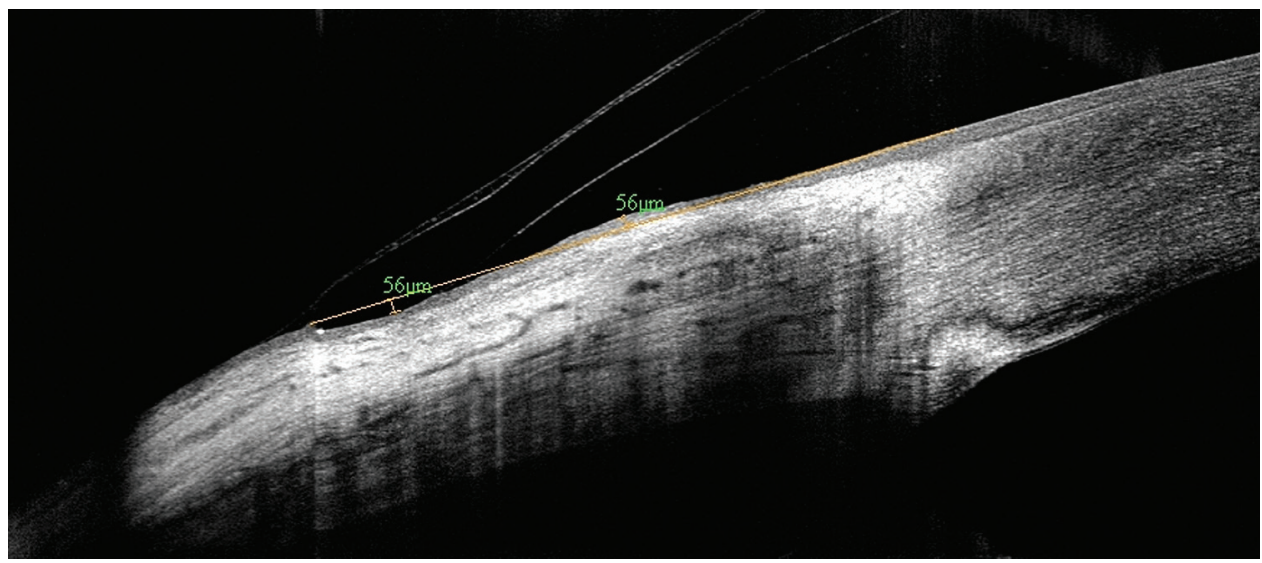

FIG. 4 Analysis of temporal and nasal scans showing conjunctival movement early after lens insertion. $\mathrm{T}=6 \mathrm{~h} 00$

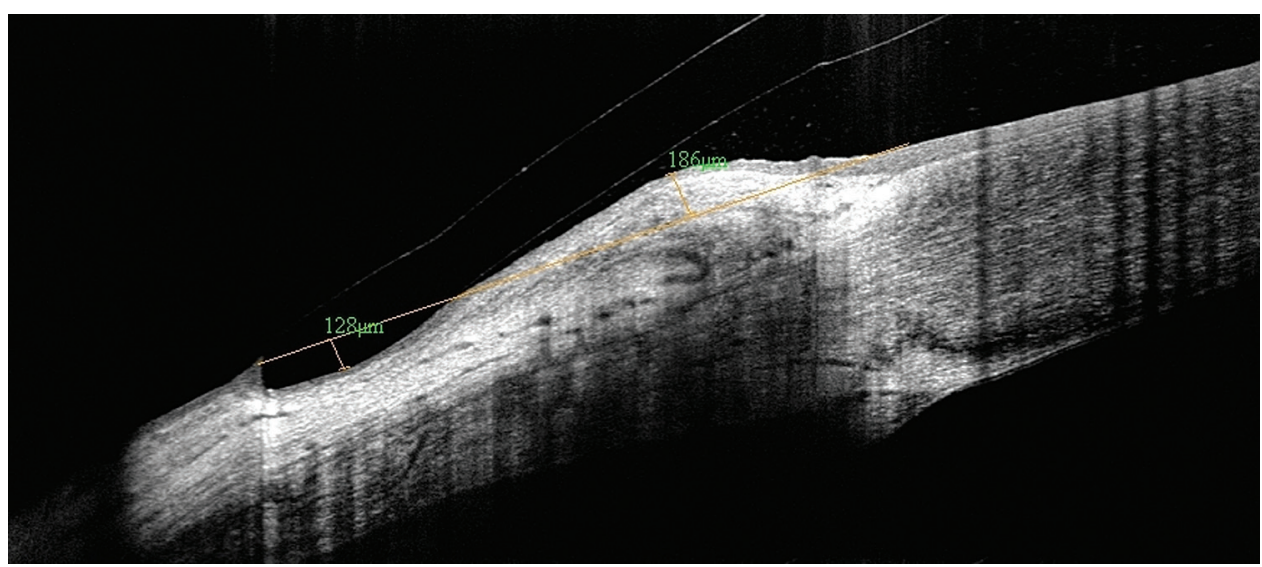

of $20 \%$ at 30 minutes and then coming to none after $2 \mathrm{~h} 00$ post insertion (see Figure 5). This was contrary to the lens fitted using saline solution in the reservoir. It took 30 minutes to identify $\mathrm{CI}$, which was present in $15 \%$ of the participants, and the number of occurrences increased to reach $35 \%$ of the observations made at $2 \mathrm{~h} 00$ post insertion and then stabilizing around $20 \%$. Due to the small number of occurrences, it was not possible to evaluate the statistical significance of time vs. treatment for this clinical finding. However, it was possible to establish the odd ratio of generating a nasal CI using a saline solution vs. gel at 3.93 $(p=0.0016 ; 95 \%$ CI $[1.68,9.20])$.

Looking at the temporal conjunctival quadrant, all subjects $(100 \%)$ showed CI from baseline to the end of the study (6h00), evolving with time. The lens fitted with gel generated an inlapse of $35.9 \pm 31.5$ um in height at baseline evolving to $84.3 \pm 48.6 \mathrm{um}$. Lenses filled with saline showed an inlapse of 64.2 $\pm 38.5 \mathrm{um}$ in height at baseline, increasing to $90.3 \pm$ 69.6 um after $6 \mathrm{~h} 00$ of wear. Paralleled to lens sinking findings, there was an effect of the factor of time $(\mathrm{F}=3.53 ; \mathrm{p}=0.0037)$ for both treatments (saline and celluvisc). A significant increase of $38.39 \pm 10.43 \mu \mathrm{m}$ $(\mathrm{t}[84]=3.68 ; \mathrm{p}=0.0072 ; 95 \% \mathrm{CI}[17.64,59.13])$ was noted 30 minutes post insertion followed by a nonsignificant decrease of $1.97 \pm 10.34 \mu \mathrm{m}(\mathrm{t}[84]=0.19$; $\mathrm{p}=1.00 ; 95 \% \mathrm{CI}[-22.52,18.58])$ between 30 minutes and 6 hours of wear. The use of gel or saline lead to the same outcome; therefore, there was no statistical

J Cont Lens Res Sci 2(1):e38-e48; May 18, 2018.

This article is distributed under the terms of the Creative Commons Attribution-Non Commercial 4.0 International License. 


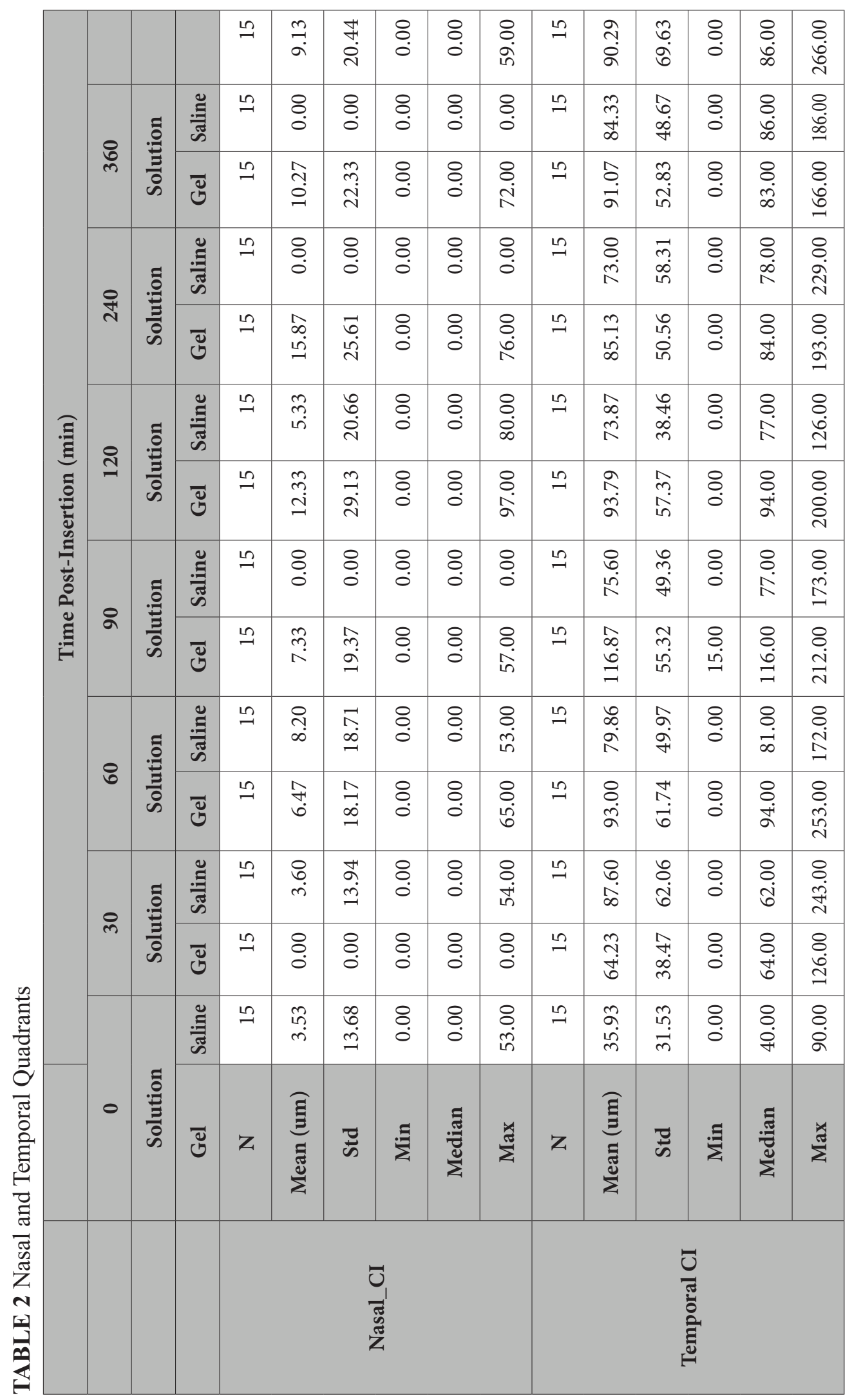

J Cont Lens Res Sci Vol 2(1):e38-e48; May 18, 2018.

This article is distributed under the terms of the Creative Commons Attribution-Non Commercial 4.0 International License. 
FIG 5 Graph showing that at baseline, 10\% of the subjects fitted with gel in the lens presented CI, reaching a peak of $20 \%$ at 30 minutes and then coming to none after $2 \mathrm{~h} 00$ post insertion.

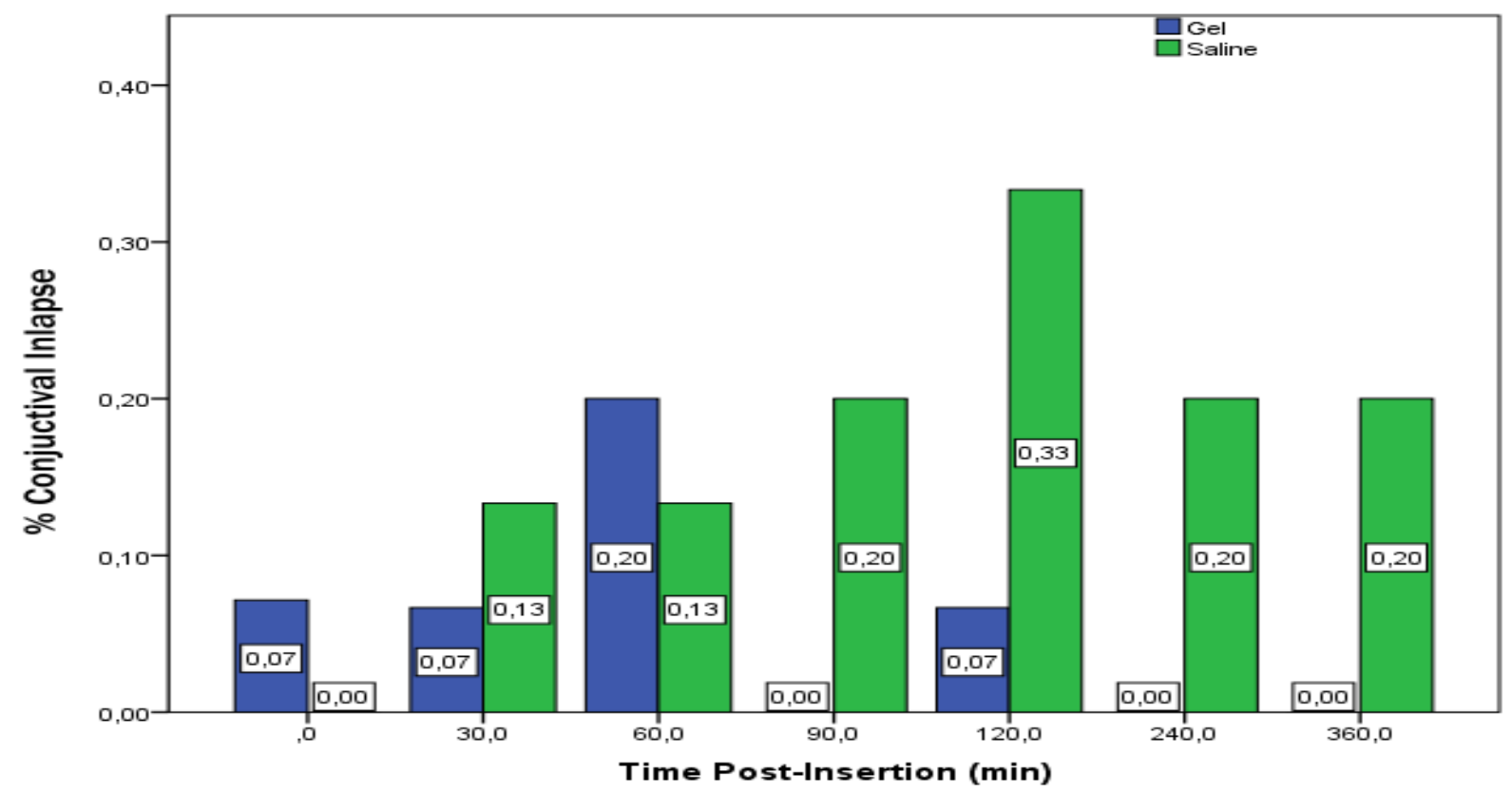

difference based on the solution used ( $\mathrm{F}=1.34 ; \mathrm{p}=0.2662)$. Consequently, the interaction between time and treatment for average temporal $\mathrm{CI}$ rate was not significant $(\mathrm{F}=1.01 ; \mathrm{p}=0.4220)$.

\section{DISCUSSION}

It is known that the amount of lens settling is influenced by multiple factors such as the condition of the underlying conjunctiva and the Tenon's capsule, which varies with age, along with the design and diameter of the scleral lens. In other words, the conjunctival response remains highly individual and may vary from one patient to another. However, in this study, It was possible to establish a significant difference between the nasal and temporal quadrant's conjunctival response since the sinking of the lens was significantly more pronounced on the former

What specifically drives the difference between the quadrants is likely related to the conjunctival physiology. From OCT studies, it is known that nasal conjunctiva is higher and flatter, compared to the temporal conjunctiva, described as lower and steeper. ${ }^{4}$ A lower elevation of the conjunctiva implies that there is more space for the tissue to move: this is confirmed with the results presented here, where all patients showed CI temporally, while just $50 \%$ of them showed the same occurrence nasally. Also, the nasal conjunctiva is flatter and more aligned with the lens' curves, reducing the possibility for the tissue to freely move.

In theory, larger lenses also tend to decenter temporally and inferiorly, which may generate a higher gap on the temporal side or an even closer lens-to-ocular surface relationship in the nasal quadrant. Finally, the lenses used in this study were made with spherical peripheries although it is obvious that conjunctiva was toric, with 220 um of sagittal height difference (nasal vs. temporal,@14 mm)in the horizontal meridian. Results would have been different if toric haptics were used to design and align more perfectly the scleral lens in all quadrants.

Another factor may explain the occurrence of CI. This relates to the lens design. CI, based on OCT scans, occurred in the surrounding area where the lens intermediate or reverse curve is located. Conjunctival tissue is then coming from a more restricted space (landing zone) to a wider space (reverse curve). Lens flexure at this particular reverse curve point may be 
also higher upon blinking, especially if the lens is made thinner. This element may play a role, acting as a pump to increase the conjunctival movement even more.

Obviously, all of these explanations are hypothetical, and our study was not designed to confirm these elements. CI was found by accident, during scans analysis of lens sinking nasally and temporally over time.

We may try to understand the clinical consequence of this phenomenon by analogy with conjunctival prolapse. It had been established that it takes several factors to generate a conjunctival prolapse: the presence of loose conjunctival tissue, located in a quadrant lower than the others adjacent to a higher limbal clearance between the cornea and the back surface of the scleral lens, and, at a lesser extent, recent history of ocular surgery or presence of conjonctivochalasis. ${ }^{17}$

In this study, all patients were under 30 years old, implying that conjunctivochalasis and loosening of the conjunctival tissue associated with age are not factors to consider. Contrary to conjunctival prolapse, occurring mostly inferiorly, CI was seen mostly in the temporal quadrant, and with limited occurrence in the nasal quadrant. This difference is probably in link with the nasal sink, as explained earlier, and a possibly decentered lens. In both situation (prolapse and $\mathrm{CI}$ ) we must keep in mind that conjunctiva will move toward the cornea whenever space allows tissue to be displaced, by the physiology of the ocular surface or second to a lens decentration. We did not specifically evaluate lens centration in this study because it was not designed that way and CI was not an expected outcome. It was not also possible to analyze this element retrospectively.

We did not evaluate the comfort of the lens, nor any other subjective aspect that may be associated with the occurrence of CI. Lenses were not worn for a long term, it is not possible to predict the clinical significance of CI over time. In comparison, the clinical significance of conjunctival prolapse is considered benign, ${ }^{18}$ despite the fact that no one knows, on the long term, if the coverage of the limbal area during lens wear may impact the physiology of the cornea, most precisely the stem cells. Some concerns also exist about the impact on tear exchange. ${ }^{19}$ There were anecdotal reports of conjunctival adhesion second to chronic conjunctival prolapse under a scleral lens, and it was resolved with surgery.

Finally, to try and understand conjunctival response to scleral lens wear (prolapse and CI), we have to look at the dynamics of the fluid under the lens from a theoretical point of view. A scleral lens is filled in with a fixed volume of a liquid solution. This fluid layer aims, in part, to help to compensate corneal irregularities ${ }^{11}$ and then to improve refractive outcome, ${ }^{12}$ but it also serves as a support system for the lens' mass, acting as a water bed.

To understand the dynamics of the fluid under its surface, a scleral lens may be considered similar to a barometer. For instance, a mercury barometer has a vertical glass tube closed at the top sitting in an open mercury-filled basin at the bottom. Atmospheric pressure place forces on the reservoir's surface and increases the pressure in the tube. Because there is a vacuum over the column, the liquid volume can expand. Over time, pressures tend to equilibrate, and the volume of liquid is stabilized as well. This model was proven valid if used with water ${ }^{13}$ so it is possible to extrapolate from it to try understanding the dynamics of fluids under a scleral lens.

Hypothetically, under a worn scleral lens, atmospheric air place forces on the tear film and the lens surface. The fluid volume inside of the lens cannot adjust to this external pressure because there is no vacuum. Consequently, the pressure would become sub-atmospheric in the reservoir because liquids cannot be compressed without putting a great deal of pressure on it. A net suction effect is then generated. This adds to another source of pressure coming from the gravity driving lens sinking. Finally, we cannot exclude that shear forces second to blinking add to this equation. Overall, these various sources generate subatmospheric pressure in the reservoir under the lens, which will generate more resistance to flow (atoms are less free to move) as well as gas diffusion (here oxygen and carbon di-oxide) into the fluid. ${ }^{14}$ This may explain that, as the lens stabilizes on the conjunctiva, tear exchange is less and less present, also taking in account that the conjunctival tissue seals off the peripheries, except if 
the design of the lens allows for a flatter relationship, or it is channel ventilated. ${ }^{15} \mathrm{~A}$ recent study confirmed that tear exchange under a scleral contact lens is low, in average $0.57( \pm 0.6) \% / \mathrm{min}$ for the first 30 minutes and $0.42 \% / \mathrm{min}$ for the 30 - to 60 -minute period. ${ }^{16}$ This is way less compared to soft silicone-hydrogel lens wear $(6.09[ \pm 2.8] \% /$ $\min$.)

In summary, the sub-atmospheric pressure under the scleral lens may explain the occurrence of known conjunctival prolapse, and to the same extent, the occurrence of the above described CI.

This study is limited by several elements. First of all, the limited number of subjects may be not sufficient to demonstrate smaller differences. This is the case for the comparison between gel and saline. On the nasal side, it was possible to find a protective effect of the gel against the development of CI, which was not correlated temporally. Intuitively, it is conceivable to consider gel as protective against lens settling and conjunctival movement, based on the higher viscosity of the fluid. However, on the temporal side, our results indicate that there is no difference in the solutions used. This makes sense only if we consider that all the elements already presented generate a reduced space to be filled with CI, and then gel may be acting against its occurrence, which may not work when space is higher, especially if the lens is decentered temporally. We also suggest that the increased pressure under the lens is high enough to counterbalance the nature of the fluid.

A second limitation is the fact that analysis of the images was not done by a masked observer. However, repeatability and accuracy of the scan analysis were already explained in details in our previous publication. ${ }^{9}$ Consequently, we are quite confident that the new clinical finding reported here, and the differences between nasal and temporal quadrants, are valid.

\section{CONCLUSION}

$\mathrm{CI}$ is identified as a new clinical phenomenon happening shortly after lens insertion, under the reverse curve of a scleral lens, mostly on the temporal quadrant, where more space is available for the conjunctival tissue to move. This finding suggests that conjunctival tissue reacts to scleral lens wear, not only in the inferior quadrant, where conjunctival prolapse is known to occur, but in every other one as well. This reaction was not seen clinically before because conjunctival displacement never reached the limbal or the corneal area. This finding also suggests that the fluid reservoir under a scleral lens is affected by sub-atmospheric internal pressure while the lens is sinking, and, because tear exchange is very limited when the lens is stabilized, this effect lasts as long as the scleral lens is worn. Further studies are needed to confirm our hypothesis.

\section{ACKNOWLEDGEMENTS}

Lenses used in this study were provided by Blanchard Labs. No other funding was obtained.

\section{REFERENCES}

1. Schornack MM, Pyle J, Patel SV. Scleral lenses in the management of ocular surface disease. Ophthalmology. 2014;121(7):1398-405.

2. Michaud L, Bennett ES, Woo SL, et al. Clinical Evaluation of Large Diameter Rigid-Gas Permeable Versus Soft Toric Contact Lenses for the Correction of Refractive Astigmatism. A MultiCenter Study. Eye Contact Lens. 2016.

3. van der Worp E, Bornman D, Ferreira DL, et al. Modern scleral contact lenses: A review. Cont Lens Anterior Eye. 2014;37(4):240-50.

4. Van der Worp E. A Guide to Scleral Lens Fitting [monograph online]. Forest Grove, OR: Pacific University: Pacific University Libraries at CommonKnowledge; 2010. $63 \mathrm{p}$.

5. De Naeyer G, Sanders D, Van der Worp E, et al. Qualitative Assessment of Scleral Shape Patterns Using a New Wide Field Ocular Surface Elevation Topographer Journal of COntact Lens Research and Science. 2017;1(1):12-22.

6. Subbaraman LN. In Focus with Current Contact Lens Materials And Designs. CL Spectrum. 2017;32(May):22-5.

7. Visser ES, Visser R, Van Lier HJ. Advantages of toric scleral lenses. Optom Vis Sci. 2006;83(4):233-6.

8. Alonso-Caneiro D, Vincent SJ, Collins MJ. Morphological changes in the conjunctiva, episclera and sclera following short-term miniscleral contact lens wear in rigid lens neophytes. Cont Lens Anterior Eye. 2016;39(1):53-61. 
9. Courey C, Michaud L. Variation of clearance considering viscosity of the solution used in the reservoir and following scleral lens wear over time. Cont Lens Anterior Eye. 2017;40(4):260-6.

10. Walker MK, Bergmanson JP, Miller WL, et al. Complications and fitting challenges associated with scleral contact lenses: A review. Cont Lens Anterior Eye. 2016;39(2):88-96.

11. Rosenthal P, Croteau A. Fluid-ventilated, gas-permeable scleral contact lens is an effective option for managing severe ocular surface disease and many corneal disorders that would otherwise require penetrating keratoplasty. Eye Contact Lens. 2005;31(3):130-4.

12. Alipour F, Behrouz MJ, Samet B. Mini-scleral lenses in the visual rehabilitation of patients after penetrating keratoplasty and deep lamellar anterior keratoplasty. Cont Lens Anterior Eye. 2015;38(1):54-8.

13. De Grys M, . Thirty Feet and Rising: Constructing and Using a Water Barometer To Explore Chemical Principles. J Chem Educ. 2003;80(10):1156.
14. Stillinger FH. Molecular dynamics study of liquid water under high compression. The Journal of Chemical Physics 1974;61:4973.

15. Romero-Rangel T, Stavrou P, Cotter J, et al. Gaspermeable scleral contact lens therapy in ocular surface disease. Am J Ophthalmol 2000;130(1):25-32.

16. Paugh JR, Chen E, Heinrich C, et al. Silicone Hydrogel and Rigid Gas-Permeable Scleral Lens Tear Exchange. Eye Contact Lens. 2018.

17. Miller WL. Managing Scleral Lens-Induced Conjunctival Prolapse. CL Spectrum. 2015;30(September):48.

18. Caroline P, Andre M. Scleral lens settling. CL Spectrum. 2012;27(May ):56.

19. Severinsky B, Behrman S, Frucht-Pery J, et al. Scleral contact lenses for visual rehabilitation after penetrating keratoplasty: long term outcomes. Cont Lens Anterior Eye. 2014;37(3):196-202. 